Volume 2 Nomor 1 Januari 2022: Halaman: 51 - 56

Doi: 10.47650/pjphsr.v2i1.321

ISSN (Online): 2777-1296

OJS: http://journal.unpacti.ac.id/index.php/pjphsr

\title{
HABIT OF CONSUMPTION OF TEA, COFFEE AND FE TABLETS WITH THE INCIDENCE OF ANEMIA IN PREGNANT WOMEN IN SIDOARJO
}

\section{Kebiasaan Konsumsi Teh, Kopi dan Tablet Fe Dengan Kejadian Anemia Pada Ibu Hamil di Sidoarjo}

Riezky Faisal Nugroho ${ }^{1 *}$, Erika Martining Wardani ${ }^{2}$

${ }^{1}$ Jurusan Gizi, Poltekkes Kemenkes Surabaya, Surabaya, Indonesia

${ }^{2}$ Fakultas Keperawatan dan Kebidanan, Universitas Nahdlatul Ulama Surabaya, Surabaya, Indonesia

*Alamat Korespondensi: riifan7@gmail.com

\section{Article Info}

Article History

Received: 13 Dec 2021

Revised : 21 Dec 2021

Accepted : 10 Jan 2022

\section{Keywords :}

Tea, coffee, Fe

tablets, anemia

\section{Kata kunci :}

Teh, kopi, tablet fe, anemia

\begin{abstract}
ABSTRAK
One of the physiological changes of women during pregnancy is a change in the blood circulation system. Erythrocyte disorders that are still common during pregnancy are anemia. The purpose of this study was to determine the habit of consuming tea, coffee and iron tablets with the incidence of anemia in pregnant women in Sidoarjo. This research is analytic, with a cross sectional approach. The population in the study was 40 respondents with a sample of 36 respondents obtained by simple random sampling technique. The instrument used is a questionnaire with a google form. The collected data was then tested with the Spearman Rank test. The results showed that there was a relationship between the habit of consuming tea $(p=0.000)$, coffee $(p=0.000)$, and Fe tablets $(p=$ 0.000 ) with the incidence of anemia in pregnant women in Sidoarjo. Preventive efforts are needed by regularly checking pregnancy with health workers to prevent anemia in pregnant women.
\end{abstract}

Salah satu perubahan fisiologis wanita saat hamil adalah perubahan pada sistem sirkulasi darah. Gangguan eritrosit yang masih sering pada saat hamil yaitu anemia. Tujuan penelitian untuk mengetahui kebiasaan Konsumsi Teh, Kopi dan Tablet Fe Dengan Kejadian Anemia Pada Ibu Hamil di Sidoarjo. Penelitian ini adalah analitik, dengan pendekatan cross sectional. Populasi dalam penelitian sebanyak 40 responden dengan sampel sebanyak 36 responden yang diperoleh dengan teknik simple random sampling. Instrumen yang digunakan adalah dengan kuesioner dengan google form. Data yang terkumpul kemudian diuji dengan uji Rank Spearman. Hasil penelitian menunjukkan terdapat pengaruh hubungan antara kebiasaan Konsumsi teh $(p=0,000)$, kopi $(p=0,000)$, dan tablet Fe $(p=0,000)$ dengan kejadian anemia pada ibu hamil di Sidoarjo. Perlu upaya preventif dengan secara berkala memeriksakan kehamilan ke petugas kesehatan guna mencegah terjadinya anemia pada ibu hamil. 


\section{PENDAHULUAN}

Salah satu perubahan fisiologis wanita saat hamil adalah perubahan pada sistem sirkulasi darah meliputi peningkatan volume darah, peningkatan pompa jantung serta peningkatan jumlah eritrosit. Jumlah eritrosit pada kondisi hamil meningkat untuk memenuhi kebutuhan transportasi oksigen yang sangat diperlukan selama kehamilan. Oksigen diperlukan untuk berbagai macam proses metabolisme perkembangan janin yang berlangsung pada tiap sel atau jaringan. Kekurangan asupan oksigen pada janin berpotensi menyebabkan gangguan tumbuh kembang janin, baik secara fisik maupun mental. Gangguan pada eritrosit yang masih sering terjadi yaitu anemia (Lisa \& Nigel, 2013).

Tahun 2018 Dinas Kesehatan Jawa Timur mencatat ada sekitar $15 \%$ ibu hamil mengalami anemia yang tergolong ringan. Sekitar $75 \%$ anemia dalam kehamilan disebabkan oleh defisiensi besi. Selain itu, defisiensi asam folat dan vitamin B12 juga penyebab yang sering ditemui (Santi, 2013). Data yang didapat dari hasil observasi di Desa Bringin Wetan Kecamatan Taman Sidoarjo, 6 dari 10 ibu hamil mengalami anemia. Ini diketahui berdasarkan pemeriksaan secara klinis dengan kondisi konjungtiva pucat dan ibu merasa lemas.

Kondisi anemia pada ibu hamil diperparah dengan kebiasaan orang Indonesia yang mengkonsumsi teh dan kopi. The dan kopi merupakan minuman yang paling banyak dikonsumsi setelah air. Aroma teh dan kopi yang harum serta rasanya yang khas membuat minuman ini banyak dikonsumsi. Teh dan kopi juga dapat digunakan sebagai antioksidan, memperbaiki sel-sel yang rusak, menghaluskan kulit, dan melangsingkan tubuh. Hal ini disebabkan karena teh dan kopi mengandung senyawa bermanfaat seperti polifenol, theofolin, tanin, serta sejumlah mineral. Sehingga teh disebut sebagai minuman kaya manfaat (Soraya, 2013). Di kalangan masyarakat mengkonsumsi teh dan kopi merupakan hal yang biasa dilakukan setiap hari. Teh dan kopi juga memiliki potensi sebagai penyebab anemia dikarenakan bisa mengabsorpsi mineral menjadi zat besi. Hal ini dikaitkan dengan peran tanin yang terdapat dalam kandungan teh. Mineral yang terdapat pada makanan merupakan pembentuk zat besi dan bila bereaksi dengan tanin yang ada pada teh, akan membentuk ikatan yang tidak larut dalam sistem pencernaan. Tanin ini dapat mengikat beberapa logam seperti zat besi, kalsium, dan aluminium, lalu membentuk ikatan kompleks secara kimiawi. Karena dalam posisi terikat terus, maka senyawa besi dan kalsium yang terdapat pada makanan sulit diserap tubuh sehingga menyebabkan penurunan zat besi ( $\mathrm{Fe}$ ) dan menyebabkan penyerapan zat besi di dalam tubuh menjadi tidak adekuat (Irianto, 2014).

Penerapan dan pemilihan makanan atau minuman dengan selalu memperhatikan jumlah, jenis, dan kandungan dan efek bagi tubuh jika dikonsumsi. Jumlah yang dimaksud adalah yang sesuai dengan kebutuhan tubuh. Kebutuhan dapat terpenuhi dengan mengkonsumsi makan yang banyak mengandung zat besi seperti telur, susu, hati, ikan, daging, kacang-kacangan (tahu, tempe, kedelai, kacang hijau), sayuran hijau (kangkung, bayam, daun singkong) dan buahbuahan serta pemberian tablet Fe. Disamping itu diperlukan juga peran perawat dan ahli gizi untuk memberikan nasihat atau informasi tentang beberapa hal yang berkaitan dengan teh seperti cara mengkonsumsi teh dan kopi yang benar, kandungan teh dan kopi, efek samping dari teh dan kopi, dan sebab akibat dari anemia.

\section{BAHAN DAN METODE}

Desain yang digunakan dalam penelitian ini adalah analitik, dengan pendekatan cross sectional. Populasi dan sampel dalam penelitian adalah semua ibu hamil di BPS Ny. NI Taman Sidoarjo sebanyak 40 responden yang diperoleh dengan teknik exhaustic sampling. Menurut Sugiono (2017), sampling jenuh adalah teknik penentuan sampel bila semua anggota populasi dijadikan sampel, hal ini dilakukan bila jumlah populasi relative kecil yaitu kurang dari 30 sampel. 
Instrumen yang digunakan dalam penelitian ini adalah dengan kuesioner yang mana ibu hamil yang telah terdata diberikan kuesioner berupa google form. Kuesioner yang digunakan sebelumnya telah dilakukan uji validitas dan uji reliabilitas bersamaan dengan pengambilan data awal. Data yang terkumpul kemudian di tabulasi dan data diproses dengan menggunakan uji Rank Spearman dengan nilai kemaknaan $\alpha=0,05$.

\section{HASIL}

Tabel 1 menunjukkan bahwa setengah (50.0\%) responden berusia 26 - 35 tahun, responden sebagian besar 19 responden (52.8\%) dengan usia kehamilan memasuki trimester II dan responden dengan paritas yang mana setengahnya 50 responden (50.0\%) merupakan primigravida dan multigravida.

Tabel 1. Karakteristik responden

\begin{tabular}{|ccc}
\hline \multirow{2}{*}{ Paritas } & \multicolumn{2}{c}{ Hasil } \\
\cline { 2 - 3 } & $\mathbf{n}$ & $\%$ \\
\hline Usia (tahun) & & \\
\hline $17-25$ & 13 & 36,1 \\
\hline $26-35$ & 18 & 50,0 \\
$36-45$ & 5 & 13,9 \\
\hline Usia kehamilan & & \\
\hline Trimester I & 7 & 19.4 \\
\hline Trimester II & 19 & 52,8 \\
\hline Trimester III & 10 & 27,8 \\
\hline Paritas & & \\
\hline Primigravida & 18 & 50,0 \\
\hline Multigravida & 18 & 50,0 \\
\hline Grandemultigravida & $\mathbf{0}$ & $\mathbf{0}$ \\
\hline
\end{tabular}

Sumber : Data Primer, (2021)

Tabel 4. Kebiasaan konsumsi teh, kopi dan tablet Fe dengan kejadian anemia

\begin{tabular}{|c|c|c|c|c|c|c|}
\hline \multirow[b]{2}{*}{ Variabel } & \multicolumn{5}{|c|}{ Kejadian Anemia } & \multirow[t]{2}{*}{$P$ value } \\
\hline & $\begin{array}{c}\text { Tidak } \\
\text { anemia } \\
\mathrm{n}(\%)\end{array}$ & $\begin{array}{c}\text { Anemia } \\
\text { ringan } \\
\mathrm{n}(\%)\end{array}$ & $\begin{array}{c}\text { Anemia } \\
\text { sedang } \\
\mathrm{n}(\%)\end{array}$ & $\begin{array}{c}\text { Anemia } \\
\text { berat } \\
n(\%)\end{array}$ & $\begin{array}{c}\text { Jumlah } \\
\text { n(\%) }\end{array}$ & \\
\hline \multicolumn{7}{|l|}{ Konsumsi Teh } \\
\hline $\mathrm{Ya}$ & $3(15,0)$ & $13(65,0)$ & $4(20,0)$ & $0(0)$ & $20(100)$ & \multirow[t]{3}{*}{0,000} \\
\hline Kadang-kadang & $3(33,3)$ & $6(66,7)$ & $0(0)$ & $0(0)$ & $9(100)$ & \\
\hline Tidak & $7(100,0)$ & 0 & 0 & 0 & $7(100)$ & \\
\hline \multicolumn{7}{|l|}{ Konsumsi Kopi } \\
\hline Ya & $3(15,0)$ & $6(66,7)$ & $4(20,0)$ & $0(0)$ & $13(100)$ & \multirow[t]{3}{*}{0,000} \\
\hline Kadang-kadang & $3(33,3)$ & $13(65,0)$ & $0(0)$ & $0(0)$ & $16(100)$ & \\
\hline Tidak & $7(100,0)$ & 0 & 0 & 0 & $7(100)$ & \\
\hline \multicolumn{7}{|c|}{ Konsumsi Tablet Fe } \\
\hline $\mathrm{Ya}$ & $3(15,0)$ & $13(65,0)$ & $4(20,0)$ & $0(0)$ & $20(100)$ & \multirow[t]{3}{*}{0,000} \\
\hline Kadang-kadang & $3(33,3)$ & $6(66,7)$ & $0(0)$ & $0(0)$ & $9(100)$ & \\
\hline Tidak & $7(100,0)$ & 0 & 0 & 0 & $7(100)$ & \\
\hline
\end{tabular}

Sumber : Data Primer, (2021)

Berdasarkan tabel 2 diatas diperoleh responden yang sering mengkonsumsi konsumsi teh sebanyak 17 responden (85\%), responden yang sering konsumsi kopi sebanyak 26 responden $(86,7 \%)$ dan responden yang sering konsumsi kopi tablet Fe sebanyak 26 responden (85\%) mengalami anemia tingkat ringan hingga sedang.
Berdasarkan hasil uji Rank Spearman dengan nilai kemaknaan $\alpha=0,05$ didapatkan nilai $\rho=0,000$ yang berarti $\rho<\alpha$ maka HO ditolak artinya ada hubungan konsumsi teh, kopi dan konsumsi tablet Fe dengan kejadian anemia pada ibu hamil di wilayah BPS Ny. NI Taman Sidoarjo. 


\section{PEMBAHASAN}

\section{Kebiasaan konsumsi teh dengan kejadian anemia}

Berdasarkan uji Rank Spearman dengan nilai kemaknaan $\alpha=0,05$ didapatkan nilai $\rho=0,000$ yang berarti $\rho<\alpha$ maka $\mathrm{HO}$ di tolak artinya ada hubungan antara konsumsi teh dengan kejadian anemia pada ibu hamil di wilayah BPS Ny. NI Taman Sidoarjo.

Menurut Tarwoto (2013), ibu hamil bisa mengalami anemia dikarenakan beberapa faktor diantaranya jarak kehamilan, status gizi, penyakit sebelumnya, perdarahan, malnutrisi, dan gangguan penyerapan (malabsorpsi). Ibu dalam kondisi hamil kebutuhan gizinya terutama kebutuhan zat besi harus tercukupi. Zat besi pada ibu hamil sangat penting karena pada saat kondisi hamil $\mathrm{Hb}$ ibu harus tetap normal sesuai dengan usia kehamilannya. Zat besi yang dibutuhkan oleh ibu bisa didapat dari makanan yang dikonsumsi ibu. Tidak semua makanan yang mengandung zat besi bisa masuk dengan baik ke dalam tubuh ibu. $\mathrm{Hal}$ ini bisa disebabkan karena adanya gangguan penyerapan (malabsorpsi) di dalam tubuh ibu. Salah satu contoh faktor yang menghambat proses penyerapan zat besi yaitu konsumsi minuman yang dikonsumsi oleh ibu.

Minuman yang dapat menghambat penyerapan zat besi adalah teh. Dalam teh terdapat salah satu kandungan yaitu tanin. Tanin yang ada di dalam kandungan teh inilah yang berperan untuk menghambat proses penyerapan zat besi. Selama ini teh digunakan ibu hamil untuk menghilangkan rasa mual dan muntah yang dialami ibu pada kehamilannya. Konsumsi teh tidak diajurkan untuk ibu hamil dikarenakan bisa menganggu penyerapan zat besi yang dikonsumsi ibu (Sudikno dan Sandjaja, 2016). Kondisi hamil inilah zat besi sangat berperan penting bagi kehamilan ibu. Pada kondisi hamil kebutuhan zat besi meningkat 2 kali lipat. Jika kondisi $\mathrm{Hb}$ tidak tercukupi dan ini terjadi secara terus menerus maka ibu hamil bisa beresiko terkena anemia. Dampak yang diakibatkan dari anemia tidak hanya terjadi pada ibu hamil tetapi juga pada pertumbuhan dan perkembangan janinnya.

Penelitian yang sama juga dilakukan oleh Setiawan dan Sugerta (2015), dimana diperoleh hasil bahwa penyerapan zat besi sangat dipengaruhi oleh kombinasi makanan yang diserap pada waktu makan makanan tertentu, terutama teh kental yang akan menimbulkan pengaruh penghambatan yang nyata pada penyerapan zat besi.

Hal ini sejalan dengan teori yang dikemukakan oleh Proverawati, (2011), kondisi tertentu mempengaruhi penyerapan zat besi dari makanan pada saluran gastrointestinal (GI) dan dari waktu ke waktu dapat menyebabkan anemia. Pada wanita hamil, anemia meningkatkan frekuensi komplikasi pada kehamilan dan persalinan, seperti meningkatkan resiko terjadinya kematian janin di dalam kandungan, melahirkan secara prematur, atau bayi lahir dengan berat badan rendah, dan juga angka kematian bayi setelah dilahirkan.

Hasil penelitian tidak semua ibu hamil yang mengkonsumsi teh mengalami anemia. Sebanyak 3 ibu hamil tidak mengalami anemia walaupun mengkonsumsi teh. Berdasarkan wawancara tidak terstruktur, konsumsi teh memang dilakukan oleh ibu tetapi ibu masih mengimbangi dengan mangkonsumsi makanan yang mengandung zat besi seperti tempe, tahu dan kacang-kacangan. Selain itu ibu juga teratur mengkonsumsi tablet Fe. Ibu hamil beranggapan konsumsi makanan yang baik dan bergizi bisa membuat kehamilannya menjadi baik dan kondisi janin dan ibu juga sehat.

Beberapa makanan sebaiknya dibatasi oleh ibu hamil yang dapat menghambat penyerapan zat besi, sehingga zat besi yang dikonsumsi terbuang melalui tinja (tidak diserap) antara lain kopi, teh, dan coklat karena makanan ini mengandung zat polifenol yang menghambat penyerapan zat besi. Diantara jenis teh, teh hitam merupakan jenis yang paling kuat menghambat penyerapan zat besi. 


\section{Kebiasaan konsumsi kopi dengan kejadian anemia}

Berdasarkan uji Rank Spearman dengan nilai kemaknaan $\alpha=0,05$ didapatkan nilai $\rho=0,000$ yang berarti $\rho<\alpha$ maka $\mathrm{HO}$ di tolak artinya ada hubungan antara konsumsi kopi dengan kejadian anemia pada ibu hamil di wilayah BPS Ny. NI Taman Sidoarjo.

Hal ini tidak sejalan dengan penelitian yang dilakukan oleh Amini (2013), yang menunjukkan hasil tidak ada hubungan antara konsumsi kafein dengan kejadian anemia karena masih banyak responden yang mengkonsumsi minuman 1-2 jam sebelum maupun sesudah makan tetapi tidak mengalami anemia. Hal ini juga dapat dilihat dari tabel analisa univariat yang menunjukkan bahwa frekuensi konsumsi kafein lebih banyak pada responden yang tidak anemia.

Menurut Setiawan dan Sugerta (2015), dalam penelitiannya diperoleh hasil bahwa senyawa tanin dari teh dan kopi yang berlebihan dalam darah akan mengganggu penyerapan zat besi. Tubuh kekurangan zat besi maka jumlah hemoglobin berkurang hingga timbul anemia. Pengaruh penghambatan penyerapan zat besi yang disebabkan oleh tanin yang ada dalam kopi dan teh dapat dihindarkan dengan cara tidak mengkonsumsi minuman tersebut setelah selesai makan. Tanin yang terdapat dalam teh dan kopi dapat menurunkan absorbsi zat besi sampai dengan $80 \%$. Minum teh atau kopi satu jam sesudah makan dapat menurunkan absorbsi hingga $85 \%$.

Erat kaitan antara konsumsi kafein dengan kejadian anemia karena dapat mempengaruhi proses penyerapan zat besi non heme dalam tubuh. Tanin yang merupakan polyphenol dan terdapat dalam teh dan kopi menghambat penyerapan besi dengan cara mengikatnya. Tanin juga diketahui membentuk ikatan larut dengan molekul besi non heme dan dengan demikian mencegah penyerapan besi non heme dalam tubuh. Oleh karena itu pentingnya menghindari minum teh atau kopi setelah makan. Sebaiknya apabila ingin meminum teh/kopi memberi jeda minimal 1-2 jam sebelum dan setelah makan.

\section{Kebiasaan konsumsi tablet fe dengan kejadian anemia}

Berdasarkan uji Rank Spearman dengan nilai kemaknaan $\alpha=0,05$ didapatkan nilai $\rho=0,000$ yang berarti $\rho<\alpha$ maka $\mathrm{HO}$ di tolak artinya ada hubungan antara konsumsi tablet fe dengan kejadian anemia pada ibu hamil di wilayah BPS Ny. NI Taman Sidoarjo.

Hal tersebut sejalan dengan hasil penelitian Sifik dan Nanang (2014), yang menyatakan bahwa terdapat hubungan yang signifikan dan positif antara sikap kepatuhan ibu dalam mengkonsumsi tablet Fe dan kadar $\mathrm{Hb}$ ibu hamil yang berkunjung di Puskesmas Kecamatan Palmerah.

Kekurangan zat besi, pendarahan usus, pendarahan, genetik, kekurangan vitamin B12, kekuranga asam folat, gangguan sumsum tulang, dan penyerapan merupakan penyebab anemia (Suprapto, dkk, 2014). Selain asupan makanan sumber zat besi kurang dari kebutuhan, juga akibat bahan makanan sumber zat besi yang dikonsumsi tingkat absorpsinya rendah atau sering konsumsi bahan makanan yang mengandung zat penghambat/inhibitor.

Anemia akibat ketidakpatuhan dalam konsumsi tablet Fe diduga disebabkan oleh rasa malas, bosan, muncul anggapan tidak penting untuk mengkonsumsi tablet $\mathrm{Fe}$, lupa, hingga efek samping dari tablet yang membuat tidak nyaman responden seperti mual, muntah, bau, dan tidak enak. Konsumsi makanan yang kurang seimbang (makanan sumber besi heme dan non heme) secara bersamaan juga menjadi salah satu penyebab anemia. Kurangnya penyerapan pada besi nonheme menyebabkan gangguan metabolisme zat besi yang mengakibatkan kekurangan hemoglobin (sel darah merah) dalam tubuh.

\section{KESIMPULAN DAN SARAN}

Berdasarkan hasil penelitian didapatkan bahwa penting mengatur diet ibu hamil dengan 
memperhatikan asupan masakan sesuai gizi yang seimbang untuk ibu hamil dengan membatasi konsumsi teh, kopi dan tablet Fe sehingga kejadian anemia bisa diminimalisir.

Upaya preventif untuk mencegah ibu hamil dengan anemia dengan menyarankan ibu untuk proaktif secara rutin memeriksakan kehamilannya, selain itu juga memperbaiki perilaku konsumsi asupan makanan yang bergizi dan sehat dengan berkonsultasi dengan ahli gizi di puskesmas terdekat untuk mengoptimalkan asupan zat gizi yang tepat selama masa kehamilan demi kesehatan dan keselamatan ibu selama proses mengandung hingga persalinan.

\section{DAFTAR PUSTAKA}

Arikunto, Suharsimi. (2013). Prosedur Penelitian Suatu Pendekatan Praktik. Jakarta: Salemba Medika.

Dinas Kesehatan Jawa Timur. (2018). Profil kesehatan provinsi jawa timur 2017. Surabaya : Dinas Kesehatan Provinsi Jawa Timur.

Irianto, Koes. (2014). Gizi seimbang dalam kesehatan reproduksi. Bandung: Alfabet.
Lisa EM, Nigel P. (2013). Physiological Changes of Pregnancy. New York: Cambridge University Press.

Proverawati, Atikah. (2011). Anemia dan anemia kehamilan. Yogyakarta: nuha medika.

Septiawan, Yudi \& Sugerta, Erta (2015). Hubungan Kebiasaan Minum Teh dengan Kejadian Anemia pada Ibu Hamil Trimester II di Puskesmas Kotabumi II Kabupaten Lampung Utara. Jurnal Kesehatan, 6(2), pp. 117-122.

DOI: http://dx.doi.org/10.26630/jk.v6i2.90

Sugiyono. (2017). Metode Penelitian Kuantitatif, Kualitatif, dan R\&D. Bandung : CV Alfabeta.

Sudikno, Sandjaja. (2016). Prevalensi dan faktor risiko anemia pada wanita usia subur di rumah tangga miskin di kabupaten Tasikmalaya dan Ciamis, provinsi Jawa Barat. jurnal kesehatan reproduksi, 7 (2), pp. 71-82. DOI : 10.22435/kespro.v7i2.4909.71-82

Tarwoto, Wasnida. (2013). Anemia pada Ibu Hamil Konsep dan Penatalaksanaan. Jakarta: Trans Info Media. 